\title{
A pergunta não respondida: Was ist musik?
}

Manoel Veiga

Universidade Federal da Bahia | Orcid: 000-002-1799-3746

\author{
pelas liçôes inesquecíveis de beleza, bondade e verdade.
}

\section{$\bigcup_{m \text { título }}$}

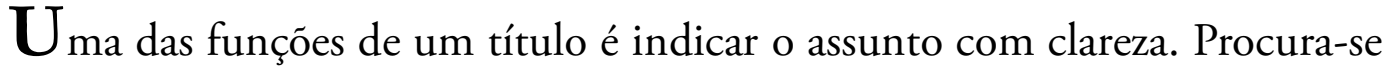
aqui, perversamente, tomar o nome de uma obra, The Unanswered Question (1908), de um dos compositores mais desconcertantes do século XX, Charles Ives (1874-1954), para refletir sobre música, seja o que for, como fenômeno emergente, isto é, de processos em que as unidades de um sistema complexo interagem entre si para chegarem a condiçóes distintas do que a soma de seus elementos constitutivos; por assim dizer, se complicam.

\section{Dois compositores americanos e duas obras}

explica: ${ }^{1}$

A descriçáo programática da obra de Charles Ives, traduzida da Wikipedia,

"Em um contexto de cordas lentas e silenciosas representando "O Silêncio dos Druidas", uma trombeta solo coloca "A Questão Perene da Existência", à qual um quarteto de "Fighting Answerers" tenta em vão dar uma resposta, ficando mais frustrado e dissonante até que eles desistem. Os três grupos de instrumentos se apresentam em tempos independentes e são colocados separadamente no palco — as cordas fora do palco."

No repertório de alusóes a música, se a resposta à "questão perene da existência" fosse a própria música (uma possibilidade, mas as interpretaçóes variam muito) valeria notar que

1 Against a background of slow, quiet strings representing "The Silence of the Druids", a solo trumpet poses "The Perennial Question of Existence", to which a woodwind quartet of "Fighting Answerers" tries vainly to provide an answer, growing more frustrated and dissonant until they give up. The three groups of instruments perform in independent tempos and are placed separately on the stage - the strings offstage.

ICTUS Music Journal vol. 15 n.2

Recebido: 2021-09-03 | Aprovado: 2021-12-22 
Ives chega a atribuir a ela "uma das formas que Deus tem de golpear o homem".

Em contrapartida, John Cage (1912-1992), outro dos provocadores americanos, chega a conceber silêncio como música em sua obra 4'33”. Nela, o mais influente dos experimentalistas americanos, descrevendo a primeira audiçáo, comenta:

O que eles [os ouvintes] achavam que era silêncio, porque não sabiam ouvir, estava cheio de sons acidentais. Você podia ouvir o vento mexendo lá fora durante o primeiro movimento. Durante o segundo, gotas de chuva começaram a bater no telhado, e durante o terceiro as próprias pessoas fizeram todos os tipos de sons interessantes enquanto falavam ou saíam.

Como também se esclarece na Wikipedia, 4’33" (pronuncia-se "quatro minutos, trinta e três segundos" ou apenas "quatro trinta e três") é uma composição de 1952, "para qualquer instrumento ou combinação de instrumentos, e a partitura instrui os artistas a não tocarem seus instrumentos durante toda a duraçáo da peça ao longo dos três movimentos". Estes são marcados pela abertura e fechamento da tampa do piano, quando este é o instrumento usado. ${ }^{2}$

Uma experiência de Cage no campo da arte conceitual o levou a uma câmara anecoica (que não produz eco, que tem baixíssimo grau de reverberação, à prova de som), na Harvard, em 1951. Essa câmara permite um silêncio absoluto uma vez que isola todo e qualquer tipo de ruído externo. Ao entrar na câmara, entretanto, Cage se deparou com a impossibilidade de alcançá-lo, devido à presença de ruídos até entáo inesperados, vindos de seu próprio corpo, como por exemplo, seu batimento cardíaco e o som do sangue que corria em suas veias. Em suma; o silêncio absoluto não existe, ou tem como única alternativa a morte do ouvinte.

Um ano após seu contacto com a câmara anecoica Cage concebeu seu famoso 4’33”. O "silêncio ruidoso" e o público rodeado por um estado de "ausência presente", são seus encantamentos.

\section{Silêncio como música e música como silêncio}

Ora, se não alcançamos o silêncio absoluto 3 , estamos diante de uma "musicophilia" generalizada, não uma alucinação (Cf. Oliver Sacks). Ou seja, de um operoso ouvido interno em paralelo aos dois ouvidos visíveis que temos. É preciso explicar isso melhor já que estamos contando ouvidos em excesso, e da audição que só existe dentro de um cérebro suficientemente evoluído. Não há som como o percebemos fora desse cérebro. Há uma audição que vem de fora e uma audição que vem de dentro, esta a musicofilía ${ }^{4}$

2 A primeira "audiçáo" do trio de três movimentos 4'33" foi dada por David Tudor em 29 de agosto de 1952, no Maverick Concert Hall, Woodstock, Nova York, como parte de um recital de música de piano contemporânea. O público o viu sentado ao piano e, para marcar o início da peça, fechar a tampa do teclado. Algum tempo depois, ele abriu-o brevemente, para marcar o fim do primeiro movimento. Esse processo se repetiu pelo segundo e terceiro movimentos que perderam o ponto. Não existe silêncio. (ainda informaçáo da Wikepedia)

3 O "silêncio" mais profundo que "ouvi" foi diante do Grand Canyon, no Arizona, um buracáo imenso à beira do deserto.

4 Falo aqui como vítima (?) de uma combinação de surdez (c. $87 \%$ ) e musicofilia, esta total e vexatoriamente intempestiva, às vezes de um mau gosto inconcebível tem associaçóes motoras (as máos movem tocando o que ouve). Seria algo assim que permitiria Beethoven compor? 


\section{Oliver Sacks: Musicophilia}

Com a mesma compaixáo e erudiçáo que ele trouxe para "The Man Who Mistook His Wife for a Hat", Oliver Sacks explora o lugar que a música ocupa no cérebro, ou que o cérebro ocupa na música, e como ela afeta a condiçáo humana. Na obra Musicophilia:Tales of Music and the Brain (New York: Knopf Doubleday, 2008) ele nos mostra uma variedade do que ele chama de "desalinhamentos musicais". Entre eles: um homem atingido por um raio que, de repente, deseja tornar-se pianista aos 42 anos; um grupo inteiro de crianças com síndrome de Williams, que são hipermusicais desde o nascimento; pessoas com "amusia", a quem uma sinfonia soa como o barulho de potes e panelas; e um homem cuja memória abrange apenas sete segundos para tudo, menos música. No meu caso, com uma perda auditiva que já ultrapassa $87 \%$, ouço música constantemente, associada a movimento dos dedos, ora peças inteiras que nunca toquei, ou que em parte esqueci e tento recuperar, ora fórmulas cadenciais, ora padróes rítmicos, ora dedilhados que tento melhorar, ora peças que jamais gostaria de voltar a ouvir. Pensei que todo mundo fosse assim ou que, pelo menos, os músicos profissionais fossem. Entre estes, tive um colega (L.A,) competente como percussionista e regente, mas totalmente incapaz de entoar um mero exercício de solfejo, como se houvesse um hiato entre a audição e a emissão vocal.

\section{Entram os antropólogos}

Antropólogos têm mantido cinco conceitos ao longo da história das teorias antropológicas: evolução, estrutura, sistema, função e relativismo cultural. Vamos aqui beliscar apenas a questão da evolução, em relação a música. Há quem a negue, como veremos depois.

Coube ao antropólogo Adolf Bastian (1826-1905) desenvolver o conceito da unidade psíquica da humanidade pelo qual é lembrado; a ideia de que todos os seres humanos compartilham uma estrutura psíquica básica. Esta tornou-se a base de outras formas de estruturalismo_do século XX, e influenciou as ideias de Carlo Jung do inconsciente coletivo.

Existe um homo musicus? Quem seria ele? (Não esquecer "ela”!). Como seria? Homo musicus - O Homem Musical, que cria, executa e ouve música - é mais velho que o Homo sapiens. O homem fazia música de alguma espécie mesmo quando não sabia como medir as coisas ou contá-las apropriadamente, e o próprio conceito de números ainda era apenas um vislumbre em seu cérebro.

\section{Evoluçáo humana}

A evolução humana é o processo evolutivo dentro da história dos primatas que levou ao surgimento do Homo sapiens como uma espécie distinta da família homínida, que inclui os grandes macacos. Esse processo envolveu o desenvolvimento gradual de traços como bipedismo humano e linguagem, encefalização, dimorfismo sexual, oposição ulnar ${ }^{5}$,

5 A oposição ulnar — o contato entre o polegar e a ponta do dedo mindinho da mesma mão — é única para o gênero Homo, incluindo Neandertais, os hominídeos e humanos anatomicamente modernos. Em outros primatas, o polegar é curto e incapaz de tocar o dedo mindinho. A oposiçáo ulnar facilita a aderência de precisão e o poder da mão humana, subjacente a todas as manipulaçóes qualificadas. 
bem como cruzamento com outros hominídeos, que indicam que a evolução humana não era linear, mas uma teia.

O estudo da evolução humana envolve diversas disciplinas científicas, incluindo antropologia física, primatologia, arqueologia, paleontologia, neurobiologia, etologia, linguística, psicologia evolutiva, embriologia e genética. Estudos genéticos mostram que primatas divergiram de outros mamíferos há cerca de 85 milhóes de ano, no período Cretáceo Tardio, e os primeiros fósseis aparecem no Paleoceno, cerca de 55 milhóes de anos atrás (informaçóes da Wikipedia).

No fim das contas, que evolução foi esta? Complicadíssima. Prestem atenção às suas mãos. São ágeis, concentram fibras nervosas e musculares; têm um polegar que multiplica dedos que hoje tocam piano e ajudam a segurar coisas, inclusive bebês que se aninham às mamães e que lhe sugam os peitos e assim, de muito cedo, desenvolvem afetos profundos. (Só dois, os peitos, preferentemente sem implante de silicone). Outros animais, vertebrados e mamíferos como nós, precisam mais que dois porque têm ninhadas. Não são bípedes, como nós, que nos pusemos de pé, deixamos de nos agarrar nos galhos e mudamos de habitat. Variam, entre os possíveis antepassados o volume do cérebro. Muito também se considera, além do bipedismo, a utilização de artefatos para facilitar ou delegar as tarefas.

O que os avanços da paleontologia e da arqueologia nos dizem é que os descendentes de Lucy, que de alguma maneira chegaram a ser Homo sapiens e únicos sobreviventes do Homo genus, andavam pela Garganta Olduval, ao norte da Tanzânia (tida como berço da espécie humana) há uns 180.000 anos. Aparentemente divergimos dos chimpanzés, nossos parentes mais próximos, entre cinco a oito milhóes de anos atrás. Temos evoluído de uma maneira não especializada, em nosso caso. Nossas mãos são máquinas para produzirem máquinas, enquanto nossas cabeçorras, debilidade física, falta de pelagem adequada, nos fazem dependentes do que inventamos.

Evidência de um comportamento avançado do Homo sapiens datando de mais de 73.000 anos vem de escavaçôes na Caverna de Blombus [Blombus Cave] ao sul da Cape Coast, na África do Sul. Os achados incluem duas peças de ocre vermelho gravadas com inscriçóes geométricas. Muitas contas perfuradas e ferramentas feitas de ossos cinzelados com apuro. Isto é importante porque se pensava que tal comportamento 'moderno' fosse muito posterior, depois da chegada desses humanos à Europa (GUERRERO; FRANCES, 2009, p, 468). ${ }^{6}$

Não sei bem o que etnomusicólogos podem fazer com informaçóes desse tipo. Alguém já pensou numa Etnomusicologia Física? Enveredaria pela organologia, provavelmente, além de muita especulaçáo. Mas atribuem aos etnomusicólogos algumas sugestóes sensatas sobre o que podem ter sido as origens de música. Justificam-se as buscas das origens porque as conhecendo saberíamos da natureza da música. Sugiro a leitura do capítulo de Nettl sobre o assunto (2005, p. 259-271).

Mais a propósito, retiro da mesma fonte informaçóes bem mais próximas de nós:

Os antigos caçadores-coletores humanos modernos da Europa viveram por alguns dos mais ásperos meio-ambientes criados pela última idade do gelo. Não obstante, este foi um tempo de rápida inovação tecnológica e mudança social, assim como expressão artística, enquanto grupos batalhavam para lidar com as condiçóes extremas (GUERRERO e FRANCES, p. 47) ${ }^{7}$

6 Estou transcrevendo do volumoso Prehistoric que contou com dezenas de colaboradores especializados. A referência terá de ir pelos editores seniores: cf. GUERREIRO; FRANCES, 2009.

7 "The early modern human Hunter-gatherer of Europe lived through some of the harshest envi- 
Estamos aqui entre 21.000 e 28.000 anos atrás. Uma evolução física havia cessado e uma verdadeira revolução cultural havia começado entre 70.000 e 30.000 anos. Ornamentos em túmulos, figurinhas femininas (mais de 350 são conhecidas), talvez símbolos ou amuletos relacionados à fertilidade e ao nascimento de crianças. A vênus da Idade da Pedra é obesa ou grávida, barriga e cadeiras exageradas, peitos volumosos, braços, pés e cabeças com menos ênfase. Algumas podem datar de 40.000 anos atrás. Temos algo parecido com as figuras femininas dos tesos funerários de Marajó, bem mais recentes, e de Santarém, peças cerâmicas que costumam ter pequenas bolas de barro dentro (chocalhos?). Entre pinturas das cavernas e achados arqueológicos já se tem evidência de possíveis instrumentos sonoros (nem necessariamente musicais, nem de fato conceitualmente instrumentos) com até 67.000 anos. Mas o complexo status de ser ou não um instrumento, do ponto de vista do confronto êmico-ético, não atinge um consenso, nem tampouco do que seja o mais antigo. O objeto esculpido chamado de flauta Divje Babe poderia estar entre 43.400 anos e os 67.000, dentro da faixa de revoluçáo cultural mencionada. Seja como for, a organologia terá de fazer-se de ponte, como indispensável ramo da Etnomusicologia que é. Nettl nos provoca com uma "etno-organologia". Por que não?

Não se pense que a aceitação desses fatos científicos tem sido tranquila. Basta lembrar o rumoroso Stokes Monkey Trial, ou Stokes Trial no qual, em 1925, confrontaram-se dois advogados famosos (Clearance Darrow e William Jenings Bryan), aquele um agnóstico e este um presbiteriano de carteirinha, e também o escritor H. L Menken e jornalistas. John Stokes e Darrow foram derrotados e Stokes multado e proibido de ensinar evolução nas escolas públicas do Tennessee. Outros estados já vinham na mesma linha, quando muito apoiando o criacionismo defensor da autoridade absoluta da Bíblia. Para os brasileiros é fácil entender isso, uma vez que na segunda década do século XXI. em plena pandemia, ainda temos um militante, caricatura de estadista, levantando a voz contra a ciência.

Negar à ciência seu domínio como metanarrativa, um dos quesitos da situação pósmoderna, significa apenas negar sua capacidade como um sistema que explique tudo, mas não significa negar sua capacidade de mandar um robô geológico a Marte. Na verdade, o Spirit, por exemplo, foi um tiro apontado em 2003 a partir do objeto onde vivemos, que revolve em torno de si (e balança) e que traslada em torno de outro, para acertar num alvo pequeníssimo, que também se move de maneira semelhante, à distância de 487 milhóes de quilômetros, em 2004, sete meses após o lançamento. Sobreviveu ativo até 2010, fazendo tudo o que se pretendeu e muito mais. ${ }^{8}$

Há regularidades que a ciência estuda a despeito da teoria da incerteza de Heisenberg, fundamentada na mecânica quântica e no estudo dos mistérios do mundo subatômico que nos tiraram a causalidade da física newtoniana. $\mathrm{O}$ mesmo diria em relação aos refinamentos de Derrida quanto a nossa capacidade de transmitir significados. Em troca, temos hoje a teoria das cordas a que somos levados pela matemática pura, sem qualquer condição de percepção de universos paralelos para os quais nossa evolução não nos preparou com os sentidos que precisaríamos ter.

O que seria bom senso (a razão que salva) é enfrentar as incertezas dos tempos atuais da maneira como somos e simplesmente dizer não aos excessos a que nos levem. A

ronments created by the last ice age. Nevertheless, this was a time of rapid technological innovation and social change as well as artistic expression, as groups battled to deal with the extreme conditions."

8 Há um clip tomado do filme IMAX "Roving Mars" de 2006. É uma versão curta editada baseada em dados reais da NASA. Cf. o YouTube How to get to Mars, no endereço $<$ http://www.youtube.com/watch?v=XRCIzZHpFtY\&feature=player embedded $>$. Acesso em 21.10.2012.

ICTUS Music Journal vol. 15 n.2 
descrença da condição pós-moderna já nos deu seu recado, mas precisamos encher o vazio a que chegamos com atos de fé eticamente produtivos, mesmo que sejamos agnósticos ${ }^{9} \mathrm{e}$ ateus: em outras palavras, sonharmos de olho aberto.

\section{As necessidades}

T eorias da cultura são superadas sem que morram de todo. Assim, do ponto de vista histórico da Antropologia Cultural, coube ao funcionalismo psicológico, dito também "puro", de Malinowski (em comparação ao estrutural de Radcliffe-Brown) a concepção de cultura vista como decorrência de necessidades biológicas e derivadas a que satisfaz, uma concepção ora criticada por ser estática. Carlos Drummond de Andrade (1902-1987), a seu modo, tem uma visão semelhante dessas necessidades que expressa poeticamente em anáforas, nem sempre fáceis de interpretar. ${ }^{10}$ (ANDRADE, 1998, p.5)

Malinowski destacou "descanso" (Relaxation) como uma de suas sete necessidades biológicas básicas individuais; sistemas de jogo e repouso, como respostas diretas, isto é organizadas, coletivas; renovação de pessoal ("é preciso substituir nós todos" diz Drummond) como necessidade instrumental; esta, respondida pela "Educação"; tudo isso em necessidades mais amplas de natureza simbólica e integrativa tais como "Transmissão de experiência por meio de princípios precisos e consistentes" (Conhecimento); "Meios de controle intelectual, emocional e pragmático do destino e do acaso" (Mágica, Religiáo); "Ritmo comunitário de recreação, exercício e repouso" (que atribuiu conjuntamente à Arte, Esportes, Jogos, e Cerimonial). Há ainda uma última das categorias de Malinowski que designou abrangentemente como "Sistemas de Pensamento e Fé".

Não gosto muito dessa junção de arte, esportes, jogos e cerimonial numa só categoria. Lembro bem da queixa de nossos colegas de dança ao se verem incluídos em escolas de educaçâoo física. Dança é mais que isso. O mínimo que causa críticas ao esquema funcional descrito não é apenas o caráter estático já mencionado da explicação de algo que muda, mas também a constatação de disfunçôes que a mim levam, pelas suas contradiçóes, a um conceito de saúde cultural (pensando no Afeganistáo e nos talibãs como uma cultura doente), que podia ser incorporado à Bioética, da qual é paradigma entre nós a Dra. Eliane Azevedo, médica e geneticista. Gostaria que estivesse aqui.

\section{Onde entram os musicólogos?}

9 Agnosticismo é a doutrina que reputa inacessível ou incognoscível ao entendimento humano a compreensão dos problemas propostos pela metafísica ou religião (a existência de Deus, o sentido da vida e do universo etc.), na medida em que ultrapassam o método empírico de comprovaçáo científica (Cf. Houaiss).

10 "É preciso casar João, / é preciso suportar Antônio, /é preciso odiar Melquíades/ é preciso substituir nós todos // É preciso salvar o país, /é preciso crer em Deus, / é preciso pagar as dívidas, / é preciso comprar um rádio, / é preciso esquecer fulana. // É preciso estudar volapuque, / é preciso estar sempre bêbado, / é preciso ler Baudelaire, / é preciso colher as flores de que rezam velhos autores. // É preciso viver com os homens, / é preciso não assassiná-los ,/ preciso ter mãos pálidas /e anunciar O FIM DO MUNDO." O "Poema das necessidades" é um dos 28 que Drummond reuniu e publicou em Sentimento do mundo. Convém lembrar que música também tem funçóes e usos. 
Devem ser músicos; há quem esqueça isto. Mas para quê? Música fala por si de maneira inteligível, mas intraduzível na afirmação de Lévi-Strauss (1991, p. 26): (minha ênfase)

... o facto de a música ser uma linguagem (...) e de, entre todas as linguagens ser esta a única que reúne as características contraditórias de ser ao mesmo tempo inteligível e intraduzível - faz do criador de música um ser igual aos deuses, e da própria música o supremo mistério das ciências do homem, contra o qual elas esbarram, e que guarda a chave do seu progresso. ${ }^{11}$

As falas sobre músicas que constituem musicologias são de fato textos (escritos, lidos, ditos, pensados) que não as representam a contento: falta o som organizado. Nem por isso são dispensáveis. Essa duplicidade entre os dois discursos, o musical e o musicológico, e a relaçáo entre eles constitui um dos problemas clássicos das musicologias. Sendo músicos, mesmo que não saibamos dizer o que música seja para todo mundo, em qualquer tempo e lugar, essa incapacidade de uma definiçáo de música torna-se um problema angustiante pelo menos para musicólogos. Isso, confesso, me tem feito transgressor. Adoro pôr o mundo de cabeça para baixo, não por pirraça, mas para que provocados, pensemos. Todos nós, aliás, somos várias coisas ao mesmo tempo. Náo posso evitar ter de vestir o hábito de monge, sem ser monge, o que a transdisciplinaridade ora exige. Mas seria ridículo me considerar antropólogo, sociólogo, psicólogo, biólogo, economista, linguista, filósofo, historiador, cientista político, crítico literário, sem nem saber o que etnomusicologia deve ser, nem música.

\section{A conversa com meu polegar}

Desenvolvemos a capacidade de falar e de apreender símbolos que, por sua vez, permitem a transmissão não presencial da cultura. Mas nós nos tornamos também uma espécie dotada da já mencionada musicofilia. Parece que "é preciso haver música", o que Drummond não disse, salvo se "É preciso comprar um rádio" for sua anáfora para música no Poema da necessidade.

Precisamos do corpo para fazer música, receber música, emitir música. Como pianista meu polegar é indispensável. Converso com ele pondo-o de encontro ao dedo mindinho e apertando (a dita oposiçấo ulnar) e mexo com os outros três dedos: só falta um teclado indiferente e teso, ao qual deva me ajustar. Não deveria ou poderia ser redondo, em vez de reto? Essa necessidade de música deve ser importante, porque desenvolvemos conchas auditivas para captar sons (não muito bem, qualquer cãozinho nos bate de cem a zero), mas não criamos pálpebras para os ouvidos. Pascal Quignard organiza seu livro Ódio à música (1996) em pequenos tratados. Num deles "Acontece que as orelhas não têm pálpebras" o autor faz uma clara apologia ao silêncio e observa: "Todo o som é invisível na forma do perfurador de envelopes... O som ignora a pele, não sabe o que é um limite. É impalpável... O som penetra. Ele é o estuprador. O ouvido é a percepção mais arcaica ao longo da história pessoal, antes mesmo do cheiro, bem antes da visão, ele se alia à noite." E no tratado que dá nome ao livro, Quignard faz uma severa crítica à música, "a única, entre todas as artes, que colaborou com o extermínio dos judeus organizado pelos alemães de 1933 a 1945 ”. Quignard indaga: "Por que a música pôde estar misturada à execução de milhares de seres

11 Este texto de $O$ cru e o cozido é sobre o fascínio que a obra de Richard Wagner exerceu sobre ele no tratamento estrutural dos mitos. 
humanos?” entre outras questóes.

Essa falta de proteção auditiva dá ao mundo dos sons uma dimensão psicológica capaz de transformar qualquer som, organizado ou não, em abjeto ruído, quando nossa privacidade é violada. Vou ser ousado, se o tempo é de especulação: cultura, linguagem, religião, música são todas produtos de uma mesma safra.

\section{A conversa com um roqueiro neurocientista}

Há pensadores proeminentes que argumentam que a música não é nada mais que um acidente evolutivo. Enfrentando-os, o roqueiro e neurocientista Daniel Levitin (Este é o seu Cérebro na Música) explora a conexão entre música - sua execução, sua composição, como ouvimos, por que gostamos dela - e o cérebro humano. Levitin afirma, com razão, que a música é fundamental para nossa espécie, talvez até mais do que a linguagem. Baseando-se nas últimas pesquisas e em exemplos musicais que vão de Mozart a Duke Ellington a Van Halen, ele revela: - Como os compositores produzem alguns dos efeitos mais prazerosos de ouvir música explorando a maneira como nossos cérebros fazem sentido do mundo - Por que estamos táo emocionalmente ligados à música que ouvimos quando adolescentes, se foi Fleetwood Mac, U2, ou Dr. Dre - Essa prática, em vez de talento, é a força motriz por trás da experiência musical - Como esses pequenos jingles insidiosos (chamados earworms) ficam presos em nós? ${ }^{12}$ Os earworms de Levitin dão-se ares de musicofilia de Sacks.

\section{Homúnculos e sua música}

Ignorando as crendices de alquimistas que os precederam, os homúnculos são representaçóes científicas das funçóes do ser humano, uma imagem corporal que o homem tem dele mesmo. Há várias versóes. Algumas dessas versóes incluem tipos femininos. Devem ser vistas como produtos da evolução humana. Refiro-me ao modelo cortical, também conhecido como o Homúnculo de Penfield ${ }^{13}$, representações físicas do córtex motor primário do resto do corpo. (Figuras 1 e 2)

Se me fosse dado fazer uma versão manoelina amadorística de um homúnculo músico (se conseguir alguém para desenhá-la), tomaria um cabide de ossos e membranas para sustentar duas estruturas nobres: o cérebro, com o sistema nervoso, representando o lado racional do homo musicus; o coração, com o sistema circulatório, representando o lado emocional. Manteria certamente os traços exagerados dos homúnculos ilustrados. Não saberia onde colocar os ouvidos, entretanto, nem quantos seriam. Sugestóes e correções seriam apreciadas com bom humor.

Figuras 1 e 2 - Homúnculo de Penfield

12 Levitin acrescenta: É um tipo de música que normalmente tem uma melodia alta, otimista e letras repetitivas que beiram entre cativante e irritante. Os earworms também são chamados de "síndrome da canção presa", "imagens musicais involuntárias", "brainworms" ou "música pegajosa".

13 Do latim "homunculus", homenzinho, procedem à maneira de mapas do córtex cerebral desenvolvidos por Wilder Penfield (1891-1976), neurocirurgiáo canadense, quando cuidava de pacientes com epilepsia. 

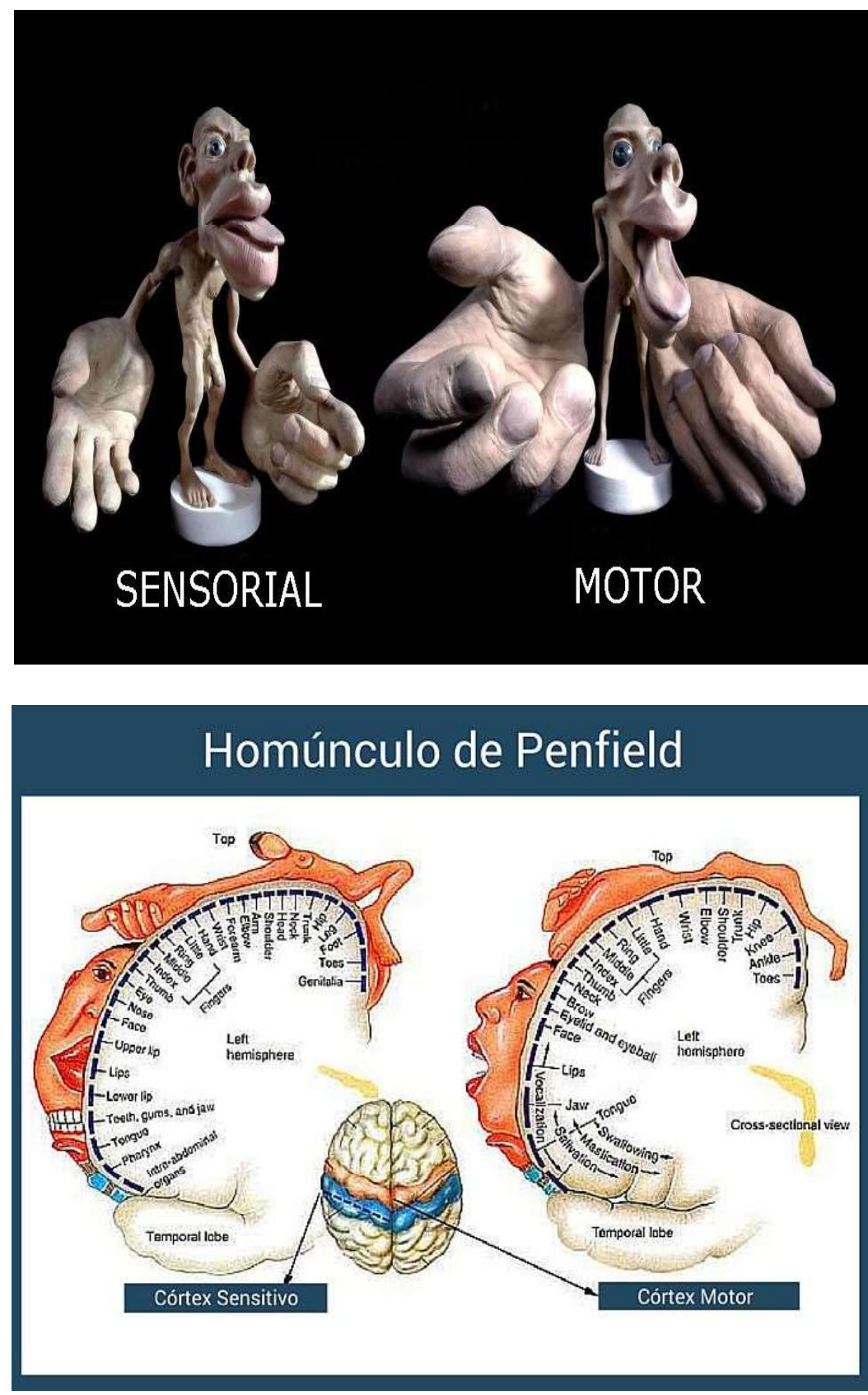

Fonte: Facebook ${ }^{14}$

Através desses ouvidos, ondas sonoras externas, meros potenciais de som, não sons propriamente ditos ainda, repito, fazem seu complexo trajeto para o cérebro. Ondas sonoras ocorrem quando dois objetos alteram suas posiçóes relativas criando pressóes e depressóes que constituem ondas esféricas que se propagam em todas as direçóes. A mera energia sonora é um tipo de energia fraca. O percurso interno se faz através de impulsos eletroquímicos até o cérebro que, suponho, os classifica, guarda como memória e permite articulá-los criativamente como música.

14 https://www.facebook.com/258220584519960/posts/895564164118929/ e https://www.facebook. com/neurocienciaemfoco/photos/pcb.1795675677252421/1795675003919155/ respectivamente. 


\section{Jules Combarieu na caçada aos elefantes}

O trajeto interno dos sons é uma rede de arrastáo, incorporando os domínios que ilustro na figura abaixo, sejam eles acústicos, matemáticos, fisiológicos, psicológicos, sociológicos, históricos, como propunha Jules Combarieu em sua obra Music, Its Laws And Evolution (1910) tentou, à maneira de uma tese, algo menos etnocêntrica que o seu tempo permitiria, comprovar sua definiçáo de música como "a arte de pensar com sons pensamentos sem conceitos." ${ }^{15}$ Associou música com magia, por exemplo, e achou que dois elefantes que conheceu eram sensíveis a música. O primeiro e o último capítulos da obra ainda me parecem válidos. Neles estou baseando o que estou qualificando como energia musical, uma capacidade de realizar trabalho enlouquecendo multidóes, como no caso dos insuportáveis trios-elétricos, ou seja, uma forma de energia forte.

O número de disciplinas com as quais música se relaciona vai de um número restrito à incidência mais direta, como queria J. H. Kwabena Nketia (1921-2019), à totalidade das disciplinas do saber humano (como afirmava Peter Crossley-Holland (1916-2001): “a única que não relacionara com música era Microbiologia ... por não haver tentado", nos dizia. Foram dois de meus grandes mestres etnomusicólogos (também compositores), na UCLA.

Figura 3 - Fluxo musical: Domínios ${ }^{16}$

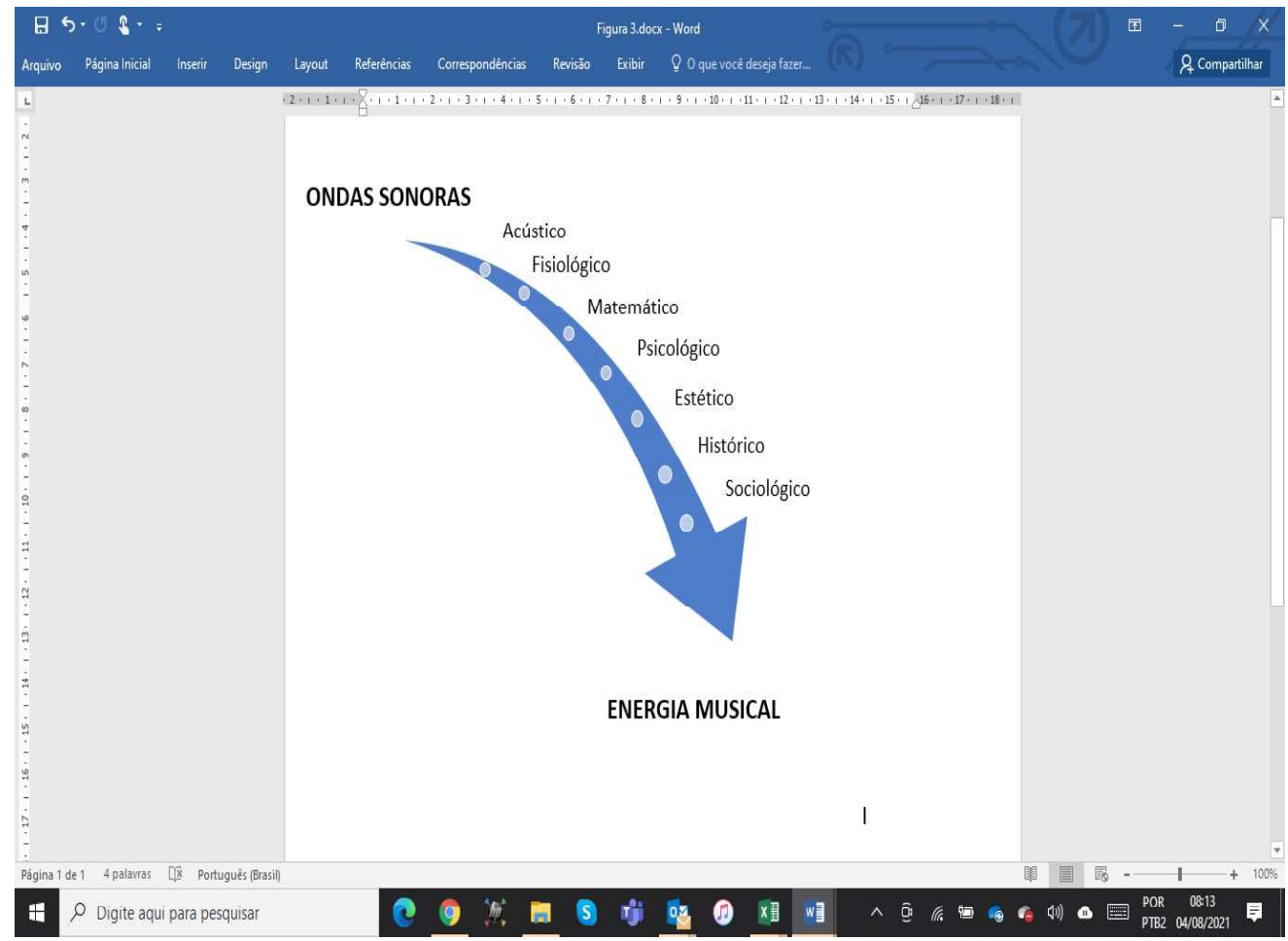

Fonte: Elaborado pelo autor.

15 O original francês, La Musique, Ses Lois, son Évolution (Paris: Flammarion, 1907) é rara e difícil de ler pelo estado do papel, mas está digitalizada. Cerifique-se de que esteja completa. Nessa edição, Combarieu incorpora sua definiçấo de música à folha de rosto "La musique est l'art de penser avec des sons", sem o complemento: "pensamentos sem conceito".

16 Agradeço a revisão desta figura ao Engo Laercio Marques Dias. 


\section{The unanswered question: $\mathrm{O}$ que é música?}

$\mathbf{E}_{\mathrm{m}}$ que pé ficamos em relação à possibilidade de uma definição de música? Entenda-se como "definição" uma afirmação única, exclusiva e aplicável a qualquer música, em qualquer época, em qualquer lugar, em qualquer função; em suma, não apenas música como um universal da cultura, mas universais empíricos da própria música. É possível ou não defini-la?

Essa é, a meu ver, é a questáo mais difícil e radical para os musicólogos. Os demais músicos geralmente não a levantam, apaixonados pelo recorte do tecido musical que praticam, isto é, sua música. Não aprendemos essa nossa música por via de tratados e especulaçóes teóricas. Seguimos São Francisco de Sales (1567-1622) nesse respeito: ${ }^{17}$ "Você aprende a falar falando, a estudar estudando, a correr correndo, a trabalhar trabalhando; e assim você aprende a amar a Deus e ao homem amando. Todos aqueles que pensam em aprender de outra forma enganam a si mesmos." Não se inicia o aprendizado de música pela teoria, portanto, mas fazendo música. Todos concordarão com Isaac Stern quando disse "Aprender música lendo sobre ela é como fazer amor pelo correio." ${ }^{18}$ A teoria vem mais tarde, quando o estudioso se dá conta de que pode pensar com sons. E ainda precisa mais tempo para distinguir que pensamento sonoro é musical, ou qual não seja. Não temos sequer um verbo genérico para o fazer música. "Musicar" existe, mas no sentido de aplicar música a um texto. Não é bem o que se quer, stricto sensu, para o fenômeno música em todos seus aspectos; uma visão científica vista do alto, singular. que se aplique a qualquer música no tempo e no espaço. Assim não se diz comumente "eu musico" no sentido genérico de tocar, ou cantar, ou trautear, ou cantarolar, compor, improvisar, reger, dançar, assobiar, em português e muitas outras línguas. ${ }^{19}$ Os recortes musicais das diversas culturas não coincidem. Em Tupi, por exemplo, o termo mais próximo que se encontra é "poracé", isto é, dançar. Nem na Grécia Antiga, tampouco, o "musiké tekné" (arte das musas) se referia apenas ao aspecto sonoro. Logo, para nosso vexame, nos damos conta de que fazemos música, ensinamos, falamos sobre ela, durante toda uma vida sem sabermos o que música seja em termos de seus universais empíricos.

A palavra "música" ou alguma outra náo terá surgido como uma definição prévia, anterior aos fenômenos a que se destinaria. Terá havido um caldo primal, indiferenciado, em que a humanidade há milênios usou sons e ruídos hoje diferenciados como língua, música, ritual, dança etc. A tentativa de se chegar a uma visão singular, totalizante, de cima, do que seja música, vai de encontro à própria natureza dela, a meu ver culturalmente específica: músicas, portanto. Não obstante, é importante lembrar o saudoso Bruno Nettl por suas valiosas tentativas de iluminar a etnomusicologia, a cuja tribo pertenço, em particular o conceito de música, seus possíveis universais e origens. ${ }^{20}$

17 Fonte: https://citacoes.in/autores/francisco-de-sales. Acesso em 22.ago.2021.

18 "Learning music by reading about it is like making love by mail."

19 O verbo "musicar" existe, mas no sentido de aplicar música a um texto. Bruno Nettl usa frequentemente "musicking", mas é um neologismo dele.

20 Com a mescla usual de humor e vigor acadêmico do grande mestre, Nettl's Elephant: On the History of Ethnomusicology (Urbana: ILL: University of Illinois Press, 2010) nos dá um capítulo magistral, o último do livro, «Music-What's That?» (pp. 215-227). Trata-se de um comentário sobre um livro de Karl Dalhaus e Hans Heinrich Eggebert, Was ist Musik? (1985). Os três primeiros capítulos de The Study of Ethnomusicology: Thirty-Three Discussions, $3^{a}$ ed. (Urbana: ILL: University of Illinois Press, 2015), representam uma terceira revisão de uma publicação original de 1983, em que houve alteraçôes de ordem e um amadurecimento

ICTUS Music Journal vol. 15 n.2 
Ao longo de vários anos venho lidando com três atoleiros conceituais (relevância, música e estudos sobre música), mas teimo ainda em colocar apelido nas coisas. Não apalpo apenas um elefante, como o fez Bruno Nettl magistralmente, mas ainda quero ver se posso caçá-lo. Sobre isso há uma lição do humor brasileiro: sobe-se numa árvore e espera-se que o elefante passe; joga-se um saco de farinha em cima dele e peneira-se com uma urupemba: o que ficar é o elefante. ${ }^{21}$

A definição filosófica de "conceito" (metaforicamente o elefante, neste caso) é o de "representação de um objeto pelo pensamento, por meio de suas características gerais" (Aurélio), mas exclusivas, devo acrescentar. A rigor, um conceito de música não deve se aplicar a algo que não seja música, pois assim não seria uma definição do que ela seja. Diante da complexidade do fenômeno musical, estamos diante de um grande problema. Uma possível saída seria dizer que todo mundo sabe: não é verdade, mas é mais ajuizado.

Os que formalizam a pergunta do que música seja não tiveram sucesso dos linguistas ao distinguirem langage (o sistema) de langue (a prática), presumivelmente linguagem e fala, ou o que estou tentando diferenciar com um simples música e músicas. $\mathrm{O}$ singular imprime um aspecto de universalidade ao conceito, que o plural não tem. O curioso é que todos nós fazemos música e nenhum de nós é capaz de defini-la num singular aplicável a qualquer tempo e lugar. Na verdade, não há isonomia entre as duas linguagens. Jean Gebser aborda isso em grande profundidade quando diz: Whatever is a speechless, genuine, and immediate expression cannot be translated into words. ${ }^{22}$ Não apenas Bruno Nettl, Jules Combarieu (tão esquecido) e Fidelino de Figueiredo, foram exímios "caçadores de elefante", mas o que resiste é uma riquíssima coleção de farelos, as belíssimas metáforas sobre música.

Tratando genericamente dos estudos musicais elaborei uma tabela sobre concepçóes distintas do fenômeno musical. Num lado coloco Deterministas como eu, etnomusicólogo; no outro, coloco Instrumentalistas, como Jamary, Bordini, Ilza (até certo ponto), compositores e teóricos da "grande música" de sua própria cultura. As dicotomias sáo arriscadas e a postura firme que imputei a Jamary (e Joseph Kerman) resulta de seu temor da superficialidade (a que eu fico sujeito). Minha cara amiga e revisora de múltiplos talentos. Ilza Nogueira pergunta, com muito acerto, se

Estaria a distinção principal entre deterministas e instrumentalistas na direção da observaçáo que se faz de um objeto (música) em seu contexto? Deterministas partem do contexto em direção ao objeto e instrumentalistas fazem o percurso inverso? Dessa forma, no percurso existem diversos "tons de cinza" e náo estamos definindo o preto e o branco, como percebi no seu quadro.

Sim. Uma outra maneira de nos referirmos a etapas do aprendizado que vão da observação, à interpretação, à explicaçáo é pensar em unidades cada vez mais abrangentes de um mesmo eixo. Esse eixo das unidades iria do microcosmo ao macrocosmo, exceto que há uma ruptura no nível das partículas elementares. (Tabela 1)

profundo no sentido da complexidade dos assuntos estudados não mais isoláveis. A Wikipedia também tem verbetes úteis sobre "definiçôes de música" e "música", tentando classificá-las por tipo e concepção, inclusive pelo enfoque das múltiplas disciplinas que a abordam, sendo as mais recentes as que vêm de neurocientistas e psicólogos cognitivos.

21 O humor brasileiro tem nosso espírito do "jeitinho". Podemos caçar jacaré olhando-o com um binóculo invertido, mais uma pinça e uma caixa de fósforo. O leitor pode bem imaginar como!

22 Qualquer que seja uma expressão sem fala, genuína e imediata não pode ser traduzida por palavras. 
Tabela 1 - Concepçôes distintas do fenômeno musical

DETERMINISTAS: pôem ênfase nos contextos e processos; as tecnologias nos fazem ser o que somos.

AXIOMAS DE BASE: música é produto do homem para o homem; comunicação, construção simbólica.

REVELAÇÃO PRIVILEGIADA, sob forma de conheci-

mento ou sentimento (concepção metafísica).

HOLISMO

\begin{tabular}{l|l}
\hline Busca de UNIVERSAIS & IDIOSSINCRASIAS \\
\hline $\begin{array}{l}\text { PLURALIDADE DE DISCURSOS e RELAÇÔES entre } \\
\text { eles: musicológicos (falas) e musicais (música). }\end{array}$ & DISCURSO MUSICAL apenas. \\
\hline ANÁLISES + HERMENÊUTICA & ANÁLISE MUSICAL = uma FÍSICA DE MÚSICA \\
\hline LÓGICA DO SOCIAL & LÓGICA DA PEÇA \\
\hline $\begin{array}{l}\text { TRANSDISCIPLINARIDADE e TRANSCULTURALI- } \\
\text { DADE }\end{array}$ & $\begin{array}{l}\text { ETNOCENTRISMO LATENTE OU DECLA- } \\
\text { RADO. }\end{array}$ \\
\hline $\begin{array}{l}\text { INCERTEZA CONSTRUTIVA em busca de uma UTO- } \\
\text { PIA. }\end{array}$ & TEORIA DE TUDO, para nada. \\
\hline $\begin{array}{l}\text { MŨSICA COMO NECESSIDADE, com FUNÇÓES E } \\
\text { USOS: COMPOR POR QUÊ? PARA QUÊ? }\end{array}$ & COMPOR COMO? \\
\hline CIÊNCIAS HUMANAS, MUSICOLOGIAS & “TEORIA” = GRAMÁTICAS? \\
\hline
\end{tabular}

Fonte: Elaborado pelo autor.

\section{Mea culpa}

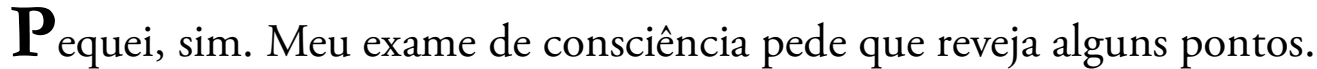

Gebser, que citei brevemente, merece o parágrafo inteiro do Ever Present Past. Tão cioso das traduções, melhor seria deixá-lo na versão inglesa: (1985: p. 454) que vai em nota: ${ }^{23}$

A essência de cada arte é, principalmente, a expressão do pré-racional e irracional, enquanto a mente tem o papel de um poder ordenador. Consequentemente, a arte reside, na maior parte, no interior da estrutura de consciência mágica e mítica. Sua raiz provavelmente está muito mais profunda, já que é a forma de expressão humana mais próxima da origem. Uma vez que a arte está predominantemente em casa nas regióes não racionais, entáo, estritamente falando, qualquer interpretação mental é inadequada. Qualquer interpretação de uma obra de arte é inevitavelmente angustiante, uma vez que o que é expresso em tons, ou assume forma em edifícios, ou em contorno ou cor, não pode ser duplicado na linguagem. Como, então, o meio da linguagem pode elucidar obras de música, pintura e arquitetura se elas criam expressões não linguísticas? O que quer que seja uma expressão sem palavras, genuína e imediata não pode ser traduzida em palavras.

23 "The essence of each and every art is, in the main, the expression of the pre-rational and irrational, while the mind has the role of an ordering power. Consequently, art resides for the most part within the magical and mythical consciousness structure. Its root probably lies much deeper since it is the form of human expression closest to origin. Since art is predominantly at home in the non-rational regions, then, strictly speaking, any mental interpretation is inappropriate. Any interpretation of a work of art is inevitably harzardous since what is expressed in tones, or assumes shape in buildings, or in outline or color, cannot be duplicated in language. How then can the medium of language elucidate works of music, painting and architecture if they create non-linguistic expressions? Whatever is a speechless, genuine, and immediate expression cannot be translated into words." 
Nettl, que abre seu corajoso verbete "Music" in Grove Music Online (2014) com prudência e um esboço de método:
(...) Os leitores certamente teráo fortes ideias dos significados denotativos e conotativos da palavra ["Música"]. Apresentar a palavra "música" como uma entrada em um dicionário de música pode implicar uma definição autoritária ou um tratamento devidamente abrangente do conceito de música, em todos os momentos, em todos os lugares e em todos os sentidos. Isso exigiria discussão de muitos pontos vista, incluindo o linguístico, biológico, psicológico, filosófico, histórico, antropológico, teológico e até mesmo legal e médico, juntamente com o musical no sentido mais amplo. Impor uma única definição voa nas feiçôes da natureza amplamente relativística, intercultural e historicamente consciente deste dicionário. ${ }^{24}$

Nettl não nos desaponta. Organiza seu verbete em três partes com importantes subdivisóes: $:^{25}$

I. A palavra: etimologia e definiçóes formais (Etimologia, Dicionários linguísticos, Enciclopédias gerais, Autoridades musicais europeias do passado, Olhando para o vernacular e para comportamento).

II. O conceito numa variedade de culturas (Cultura ocidental contemporânea, Leste da Ásia, Irã e Oriente Médio, Índia, Algumas culturas africanas, Algumas culturas Ameríndias e Oceaníacas).

III. O conceito de música em estudos avançados [scholarship] (Circunscrevendo a palavra e o conceito, Algumas características centrais, Música entre as artes, Música entre os domínios da cultura, A função de música, Classificação ou Tipologia, Música como um fenômeno universal, Sobre as origens de música, Bibliografia).

Uma das características de Nettl, além do humor, da abrangência de seus conhecimentos, é que ele não desiste. Tampouco se posiciona, limitando-se a expor possibilidades: na realidade, nenhuma afirmação por uma única pessoa é suficiente. Nettl fecha seu verbete, cerca de trinta páginas depois, nos seguintes termos: ${ }^{26}$

O objetivo deste artigo é, de fato, mostrar que, na concepçáo da música, o mundo é um pastiche de diversidade, e assim o autor é obrigado a evitar o compromisso com uma única posição. Há pouca dúvida de que cada leitor desta obra acredita firmemente na existência de música e subscreve uma concepção específica, talvez pessoal e certamente derivada da cultura. No entanto, se aventura a afirmar que não há ninguém que possa imaginar a vida sem ela.

24 ["Music" is] The principal subject of the publication at hand [The Grove Online], whose readers will almost certainly have strong ideas of the denotative and connotative meanings of the word. Presenting the word 'music' as an entry in a dictionary of music may imply either an authoritative definition or a properly comprehensive treatment of the concept of music, at all times, in all places and in all senses. That last would require discussion from many vintage points, including the linguistic, biological, psychological, philosophical, historical, anthropological, theological, and even legal and medical, along with the musical in the widest sense. Imposing a single definition flies in the face of the broadly relativistic, intercultural, and historically conscious natures of this dictionary

25 Para comentários esclarecedores, o verbete "Bruno Nettl: Music" da Wikipedia, acessado em 24.08.2021, é recomendável.

26 The purpose of this article is, indeed, to show that, in its conception of music, the world is a pastiche of diversity, and thus the author is obliged to avoid commitment to a single position. There is little doubt that each reader of this work believes firmly in the existence of music and subscribes to a specific, perhaps personal and surely culture-derived conception of it. Yet one ventures to assert that there is none who can imagine life without it.

ISSN 1516-2737 | e-ISSN 2238-6599 


\section{(Nettl se esqueceu do Ayatollah Khomeinie nessa sua frase derradeira!)}

Tenho assim de confessar que minha própria posição $\bigotimes$ tendo-os trazido aqui sabendo que não há resposta única para o que música seja $\bigotimes$ o que me justifica são as incontáveis metáforas sobre música que constituem o farelo mais rico de nossa caça ao elefante. Uma vez que Nettl nunca menciona Combarieu, que eu saiba, vamos encerrar com uma pequena citação dele, quando baixa a guarda: ${ }^{27}$ (1910: p. 320)

Uma arte como esta, apesar do conhecimento técnico com o qual foi enriquecida, é cheia de simplicidade: expressa, exalta e amplia o sentimento de vida que aspira a um estado mais elevado; e é maravilhoso que tantas coisas tão grosseiramente indicadas pela análise devam ser contidas em um sopro de ar que passa...

$27 \quad$ An art such as this, in spite of the technical knowledge with which it has been enriched, is full of simplicity: it expresses, exalts, and magnifies the feeling of life which aspires to a higher state; and it is marvelous that so many things so coarsely indicated by analysis should be contained in a passing breath of air.... 


\section{Bibliografia}

ABBAGNANO, Nicola. Dicionário de Filosofia. Tradução coordenada e revista por Alfredo Bosi. 2a ed. São Paulo: Mestre Jou, 1982. s.v. "Música”.pp. 659-663

ANDRADE, Carlos Drummond. Sentimento do mundo.Rio de Janeiro: Record, 1998.

COMBARIEU, Jules. Music, Its Laws And Evolution. The International Scientific Series, editada por F. Legge. Londres: Kegan Paul, Trench, Trübner, 1910.

CROFTON, Ian; FRASER, Donald (comp.). A Dictionary of Musical Quotations. New York: Schirmer Books, 1985.

FEUERSTEIN, G. Structures of Consciousness: The Genius of Jean Gebser, An Introduction and Critique. Lower Lake, CA: Integral Publishing, 1987.

GEBSER, Jean. The Ever-Present Origin. Tradução autorizada por Noel Barstad com Algis Mickunas. Athens, OH: Ohio University Press, 1985.

GUERRERO, Angeles Gaviro; FRANCES, Peter (Ed.). Prehistoric. Londres: Kindersley Dorling, 2009.

LANGER, Susanne K. Filosofia em Nova Chave. Trad. e rev. de Janete Meiches e J. Guinsburg. 2 ed. São Paulo: Perspective, 1989.

LANGNESS, L.L. The Study of Culture, ed. rev. Novato, CA: Chandler and Sharp, 1987.

LÉVI-STRAUSS, Claude. O cru e o cozido: Mitológicas.Tradução de Beatriz Perrone-Moisés. São Paulo: Editora Brasiliense, s.d.

LEVITIN, Daniel J. This is Your Brain on Music: The Science of a Human Obsession. :Penguin Books Group, 2007.

MALINOWSKI, Bronislaw. A Scientific Theory of Culture and Other Essays. Chapel Hill: University of North Carolina Press, 1944.

MITHEN, Steven. The Prehistory of theMind: The cognitive origins of art, religion and science. Londres: Thames and Hudson, 1996.

MOORE, Jerry D. Visions of Culture: An Introduction to Anthropological Theories and Theorists. 3.ed. Lanham, MD: AltaMira Press, 2009.

NETTL, Bruno. "Music”, rev. atual., in Grove Music Online: Oxford Music Online, 2014. Acesso em 29 mar. 2020.

NETTL, Bruno. Nettl's elephant: On the History of Ethnomusicology. Prefácio de Anthony Seeger. Urbana: University of Illinois Press, 2010.

NETTL, Bruno. The Study of Ethnomusicology: Thirty-three Discussions. Urbana: University of Illinois Press, 2015. 
NOGUEIRA, Ilza. Comunicação pessoal por email, em 30.08.2021.

PERRY, Richard J. Five Key-concepts in Anthropological Thinking. Upper Saddle River, NJ: Prentice-Hall, 2003.

QUIGNARD, Pascal. Ódio à música. - Rio de Janeiro: Rocco, 1999.

ROUGET, Gilbert. La musique et la transe: Esquisse d'une théorie générale dês relations de la musique et de la possession. Paris: Gallimard, 1980.

SACKS, Oliver. Alucinaçôes musicais: Relatos sobre a música e o cérebro. Tradução de Laura Teixeira Motta. São Paulo: Companhia das Letras, 2007.

SACKS, Oliver. Musicophilia: Tales of Music and the Brain. rev. aum. New York: Knopf Doubleday, 2008.

SOTUYO, Pablo (org. e ed.), Por uma etnomusicologia brasileira: Festschrift Manuel Veiga. Salvador: Programa de Pós-graduação em Música da Universidade Federal da Bahia, 2004.

VEIGA,Manuel. "Uma reflexão sobre relevância em música e seus estudos.” In SOTUYO, Pablo (Org.) Musicologias sem fronteiras. Salvador: EDUFBA, 2020. Pp. 13-37.

VEIGA, Manuel. O estudo e o ensino de música: a busca (de um roteiro de vida). Postado no SONARE. 